\title{
What Is the Effect of Using Mobile Augmented Reality in K12 Inquiry-Based Learning?
}

\author{
Margus Pedaste*(D), Geidi Mitt and Teele Jürivete \\ Institute of Education, University of Tartu, Tartu 50103, Estonia; geidi.mitt@ut.ee (G.M.); \\ teele.jurivete@ut.ee (T.J.) \\ * Correspondence: margus.pedaste@ut.ee
}

Received: 28 February 2020; Accepted: 30 March 2020; Published: 1 April 2020

\begin{abstract}
A systematic review of the potential of implementing augmented reality (AR) in inquiry-based learning was conducted. We considered the purposes, potential advantages, application characteristics and the effects of using AR in inquiry-based learning. The findings reveal that AR, in the context of inquiry-based learning, is mostly implemented successfully to achieve cognitive and, less often, motivational and emotional learning goals. The AR solutions have mainly been applied in the Conceptualization phase and less in the Investigation phase. The affordances of AR in the Orientation, Conclusion and Discussion phases need to be applied in further studies.
\end{abstract}

Keywords: mobile augmented reality; inquiry-based learning; K12 education; systematic literature review

\section{Introduction}

According to the Education 4.0 Framework that operationalizes the fourth industrial revolution in education, technological innovation is transforming education. People need new skills to use contemporary technologies meaningfully in the learning process. Technology has improved very fast, and it has been difficult to apply many of its affordances in education. The concept of affordances was introduced by Gibson [1] more than forty years ago to specify the properties of an object that allow use in one way or another. This does not mean that the object has been used in this way, but it could be potentially used thus, because it has specific properties. Hutchby [2] applied the concept of affordances in the context of using technology and argued that technological affordances are "functional and relational aspects which frame, while not determining, the possibilities for agentic action in relation to an object" (p 444). He found that the concept was needed to contrast social constructivism that focused heavily on the social construction of the learning process. This means that the learning process can be designed in a social context only within the limits of the objects that form a material environment around the learners. Of course, the environment does not constitute only the physical world of objects but also cultural and structural parameters-other people, their attitudes towards technology, and the learning process and rules set by the people in society. In this way, the decision to use or not use some specific technology in an educational context depends on the technology, the environment and the people. This is in line with the ecological model of agency (see [3,4]), which highlights that the agency in decision making is not the ability of a human but a combination of the competence and purposes of the human in the context of the environmental conditions. In order to make a decision to use some technology in a learning situation depends first on the professional competence of the learner (do I have the needed knowledge and skills, do I value the use of technology?) and his/her purposes (do I have goals that could be achieved using technology, do I have goals to achieve transferable skills and positive attitudes towards technology?). However, it also depends on the environment in a specific situation and on the affordances of the technology. The technology will be taken into active use only if 
it has the properties needed in the particular situation and, more likely, if the environment supports it-if the cultural, structural and material conditions are supportive. For example, other learners should also have a positive attitude towards using the technology in order to avoid social exclusion, and there should be available enough time and technical support for using this technology, and enough budget to equip all learners with the technology.

Due to different reasons, technology has been used in education much less than it has the potential to be according to its affordances. For example, Pedaste and Leijen [5] found in a review that educational technologies are mainly designed to improve subject knowledge and skills, or to support collaboration and self-regulation, but not usually to enhance students' learning skills and subjective well-being. A similar finding was revealed in a literature review studying the use of open learner models in the context of self-regulated learning [6]. The study showed that technology (open learner models in this case) has been mainly used to support students' cognitive/metacognitive and motivational learning processes, but not their emotional ones. Panadero's [7] framework describing four main areas of self-regulated learning - cognitive, metacognitive, motivational and emotional—was used in this case. We found the same framework to be useful in our study because inquiry-based learning, which is our main focus, is also a self-regulated learning approach. In the context of learning with mobile phones and tablets, Pedaste et al. [8] found that only five percent of the students in middle school use their devices actively in different ways for learning according to their affordances-for searching and sharing information, communication and collaboration, and content creation. This is also a good example showing that the affordances of the technology are not always used, even if the students have the skills but lack purpose or support from the teacher-agency is formed by a combination of these. Thus, it seems that the potential of technology affordances is usually not fully applied in educational settings. The current study focuses on one of the emerging technologies-augmented reality-and discovers how its affordances have been applied in the context of inquiry-based learning and how to further open its potential.

Augmented reality (AR) combines the real and the virtual worlds. It can be defined as a technology that enriches the real world with digital elements [9] such as 3D animations, images or videos. The coherence of the real and the virtual world is achieved through a camera that is connected to a digital device (see [10]). AR can be used with different devices such as smartphones, tablets, laptops, computers or head-mounted displays. In any of these cases, the digital elements are superimposed on a user's real-world view. There are two main ways the AR application types can be described. First, the types can be divided into marker-based and markerless AR applications [11]. Marker-based applications use simple markers such as images and QR-codes to display the digital information. Markerless applications usually require a GPS signal and therefore depend on the location, but can also use sensors as physical inputs in order to display the virtual information. Second, Cheng and Tsai [12] divide the application types into location-based and image-based AR. Location-based applications need position data to identify the location, and image-based AR applications work by registering the position of digital objects using real-world images. In addition to these types, AR applications can also be described based on the ARCore and ARKit frameworks [13]. Both frameworks support the capability of detecting flat surfaces, enabling to project AR objects accurately in relation to the physical world, e.g., on a table or floor. The AR objects are displayed on the surface, and the position of the objects is recognized in cooperation with gyroscopes and cameras.

There are different technologies to augment reality for learning. High-quality solutions need a headset, e.g., Microsoft HoloLens. These solutions are usually too expensive for schools, and the content development for high-quality headsets is more expensive and demanding than solutions that use mobile phones and tablets to augment the real world. Therefore, we focus in the current study on mobile AR, which we define as AR solutions that need mobile phones or tablets. Mobile AR has currently become more accessible and therefore emerged in the field of education. AR technologies provide several educational affordances. For example, according to the literature review from $\mathrm{Wu}$ et al. [14], there are five main affordances of using AR in education, but not all of them may 
be solely linked to AR. First, learners could visualize objects and places that could not easily be seen in real life; for example, objects that are too small to see with the naked eye, such as molecules and atomic structures, or places that could be dangerous or impossible to visit, such as the deep ocean floor and high mountains. Secondly, Wu et al. [14] point out that AR could be efficient for interacting with 3D objects. This means that learners could view the objects from different sides and go inside them. This could be very helpful in learning spatial skills in geometry, or even in better understanding complex objects in biology, e.g., the structures of a cell. Third, mobile AR could provide possibilities for collaborative and situated learning. For instance, several educational mobile-AR games have been developed that could support learning in different ways. Moreover, AR could enable learners to feel that they are in different places with others and, thus, provide more realistic experiences. That kind of immersiveness might be very important in learning about social-scientific issues and improving empathy in various situations, e.g., war refugees in a camp, or children with special educational needs in different contexts. Finally, AR technologies could also bridge formal and informal learning. For example, students could use AR applications at school during classes, but also at some other places like at museums or in botanical gardens.

In recent years, several literature reviews have been published focusing on the educational aspects of using AR technologies. Akçayır and Akçayır [15] identified the gaps in AR research in education as they analyzed articles from up to 2015. They focused on the published studies' time of distribution, learner types, technologies, and the educational advantages and challenges of using AR. They found that the learner type was mainly K12 students, the most commonly preferred technology was mobile devices, and researchers have focused largely on developing students' academic performance. Saltan and Arslan [16] analyzed papers from the period 2012 to 2016 in their literature review and focused on the technologies, pedagogical approaches, affordances, educational outcomes and limitations of using AR in education. They found that the affordance of AR was mainly knowledge comprehension. In their review, they also noticed that marker-based applications are often used and the main limitation of the papers was their small sample size. Altinpulluk [17] determined the trends of using AR in education between the period of 2006 to 2016 . He focused on methods, data collection, fields of study, application types and technologies, assets, physical environments, senses, countries, continents, and the most used keywords regarding the application of AR in education. He found that the main educational advantages of using AR were improving academic achievement, improving motivation, improving perception, improving satisfaction and improving interaction. Most of the studies were carried out in the field of science, and mobile AR applications were mainly used. In 2018, Ibáñez and Delgado-Kloos [18] published a literature review focusing on the use of AR for Science, Technology, Engineering and Mathematics (STEM) learning. They analyzed articles from the period 2010 to 2017 and investigated the main characteristics and design features, instructional processes and measured outcomes of using AR in STEM education. Most AR applications offered simulation or exploration activities for learners, and students' conceptual understanding was mainly measured. The main evaluated affective learning outcomes were motivation, enjoyment, attitude and engagement. Yilmaz [19] concentrated on AR trends between the period 2016 to 2017. She reported that during these two years, AR technology has mostly been used in primary and graduate education, and the most explored field of study was science. Mobile AR and marker-based applications were used in preference to other possibilities. The main advantages of using AR for educational purposes were better academic achievement, higher motivation and better attitude. In sum, these systematic literature reviews revealed that the main educational advantages could be the increase in learning performance and higher motivation levels. On the other hand, researchers have recently started looking into the potential of interactive AR technologies that could be even more beneficial in enabling inquiry-based learning [20]. The potential of implementing AR in inquiry-based learning has not been revealed, because generalizations based on the studies have not been made yet.

Inquiry-based learning has been considered as one of the key methods in STEM learning in recent years, although it has been applied more and more in other subject areas as well. It has been used 
because it enables learners to learn scientific thinking in whatever subject area. For example, in STEM, learners learn how to define problems, formulate hypotheses, plan and conduct experiments, make inferences, and communicate the process and outcomes to others to discuss these with them. The main aim of the inquiry-based approach is to solve a problem by applying inquiry skills; however, it is also important that it is a self-regulated process that starts from personal interest and continues by formulating research questions and/or hypotheses, planning data collection, collecting data and making conclusions (based on [21-24]). The inquiry process is quite complex, and therefore, it has been divided into different phases. Pedaste et al. [25] differentiated five general inquiry phases in their review: Orientation, Conceptualization, Investigation, Conclusion and Discussion. According to their framework, inquiry starts from Orientation. In the Conceptualization phase they specify Questioning and Hypothesis Generation sub-phases. The Investigation phase has been divided into Exploration, Experimentation and Data Interpretation sub-phases. The final phase of the inquiry process is the Conclusion and Discussion phase, which is seen in parallel with all the other phases. It consists of Communication and Reflection sub-phases. According to the affordances, AR could be mainly used in the Orientation, Conceptualization and Investigation phases. For example, in the Orientation phase, learners could get acquainted with the situation where the problem occurs. If the situation, when presented in AR, could present more information, then learners' awareness when defining the problems was higher. In the Conceptualization phase, one could discover information about the object that triggers the augmented world, but it could be also possible to augment the real environment with new objects according to the scenario. In the Investigation phase, it might be possible to interact with the objects under investigation and to collect data about them. In an advanced scenario it could be possible to manipulate the object and run experiments. A few less affordances of AR could be seen in the case of the Conclusion and Discussion phases. Indeed, in the Discussion phase, one might develop a scenario where a virtual assistant could ask questions from the learners and reply to questions.

Thus, AR has many affordances for application in inquiry-based learning, and to achieve not only the cognitive learning outcomes, but also the metacognitive, motivational and emotional aspects of learning. However, it's not known how widely AR has been used for these purposes and what the effects and detected limitations have been. Therefore, our study used a systematic literature review approach to analyze studies that have applied an inquiry-based learning approach and used AR in one or more inquiry phases. Our intention was to focus on mobile AR, because this is accessible for most students worldwide. More specifically, four research questions were formulated:

1. What are the purposes of using mobile AR in an inquiry-based learning process?

2. What are the potential advantages of combining AR with inquiry-based learning?

3. What are the characteristics of AR-based applications used for inquiry-based learning?

4. What has been the effect of applying AR in inquiry-based learning?

\section{Materials and Methods}

The search was conducted in October, 2019, using an EBSCOhost Web service to access several databases: ERIC, Web of Science, IEEExplore, ACM Digital Library, Springer and Scopus. These databases cover the journals indexed in databases covering smaller amounts of publications, such as Web of Science. The advanced search function and the following search terms were selected: "augmented reality" OR "mixed reality" AND "learning" AND "inquiry". Academic journals, conference materials and books were selected as the types of sources. The time period was specified as 2015-2019 because we were interested in the use of AR in the past five years, because the earlier studies might understand AR more broadly than as it was defined in the current study.

The search resulted in 33 articles (see Figure 1). In addition, the list of references of the found articles were analyzed and this revealed 22 more articles for our analyses. Among the 55 identified records, two duplicates were removed, and the remaining 53 articles were screened by two researchers against the inclusion and exclusion criteria based on their titles and abstracts. During this screening 
phase, three inclusion criteria were adopted: focus on K12 education (age group from seven to 18), mobile-AR (excluding headset-based solutions) and inquiry-based learning (the broader term problem-based learning was considered under this because of the significant overlap of these two approaches). Both researchers evaluated each paper and excluded it only if it was clear that at least one of three inclusion criteria was not met. In case of doubt, the article was left in the analysis to make the decision based on the analysis of the full text. The consistency of the evaluations of the two researchers was found using Cohen's Weighted Kappa. The result was 0.757, showing quite high agreement between the two raters. In case of differences, the evaluation of a third researcher was asked for, and the final decision about the inclusion or exclusion of the article was made collectively. If it was not possible to make the final decision based on the titles and abstracts only, then the full text of the article was studied. In the phase of screening the titles and abstracts, 21 records were excluded, and in the case of full texts, 17 more articles were excluded. Therefore, 15 articles were included in the final analysis of our study. The only exclusion criterion applied in the selection process was the focus of the article being on head-mounted displays.

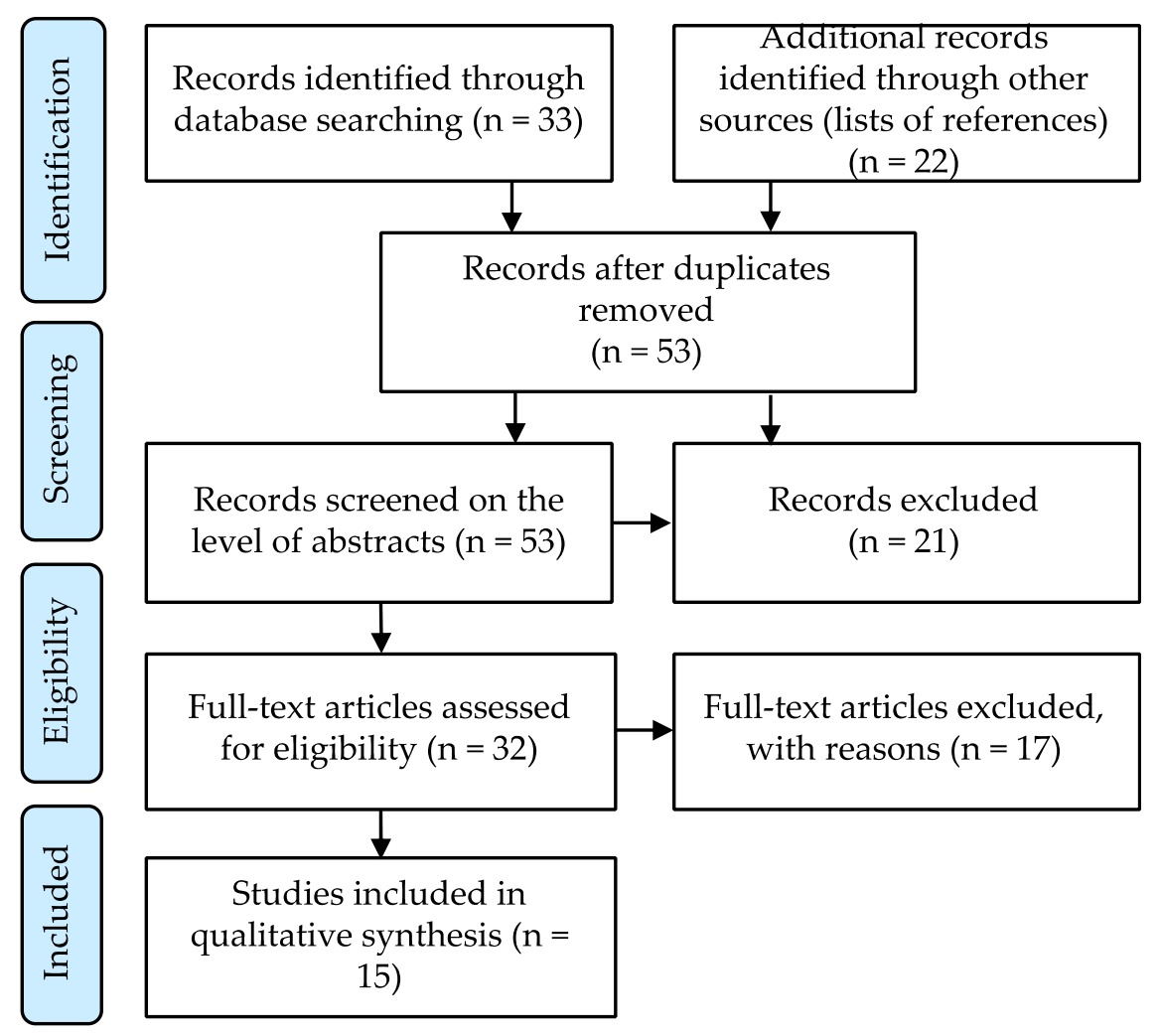

Figure 1. A flow chart of the search and inclusion process.

The coding schema for analyzing all found articles was developed through discussion of the authors based on the research questions. First, the purposes of using mobile AR, potential advantages in inquiry-based learning, characteristics of AR-based applications, and effect of applying AR in inquiry-based learning were described according to the research questions. In addition, some background information was described: the country of the study, the age group, the number of learners and the subject of the study. Finally, we also focused on how the validity and reliability of the study were ensured. Unfortunately, it appeared that in the case of six out of 15 studies, this was not clearly described in the article, and we had to make our judgement based on the presentation of methods and findings of the study. This is one of the limitations of the current review. Therefore, the conclusions made in the current study cannot be taken as generalizations, but as ideas that need to be considered in designing new AR solutions for inquiry-based learning. 


\section{Results}

Our literature review revealed 15 articles that were in line with the specified inclusion criteria-focused on applying mobile AR for inquiry-based problem solving. In eight of the articles, the AR application was used with elementary school students (aged 8-11 years), while seven studies focused on middle school (age 12-14(15) years), and only two studies were carried out at the high school level (age (15)16-18 years). One of those studies reported the use of AR at both the elementary and high school levels. The sample size of the studies varied from 16 to 93 (average 50). The studies were all conducted in one country-there were missing studies testing the same systems in different cultural contexts, which covered three continents: North America, Asia and Europe. More than one study by different authors was conducted in Taiwan (four) and USA (three). From Cyprus, we found two studies, but these were published by the same research group. In addition, there was one study reported from Germany, Greece, Portugal, Spain, Mexico and Indonesia. We searched for the studies published since 2015. A slight increase in published articles according to our inclusion criteria was found in 2019 - in this year, six articles were published and one more was available online, although it will be issued in the journal number published in 2020.

\subsection{Purposes of Using $A R$ in an Inquiry-Based Learning Process}

Although inquiry-based learning is usually applied in the context of science education, we found that the AR scenarios open up the potential of inquiry-based learning in other fields of studies as well. Out of the analyzed 15 articles, nine were carried out in learning sciences, three in history, three in mathematics and one in computer science. One of those papers focused on two case studies in the fields of history and environmental sciences. Of nine studies that were carried out in the sciences, two studies were in the field of physics, two in ecology, two in environmental sciences, one in astronomy and one in general natural sciences, and there was one interdisciplinary study focusing on both geography and physics. Out of the three studies in mathematics, two focused on geometry.

AR was mostly implemented in an inquiry-based learning process to achieve cognitive and motivational learning goals (see Table 1). Cognitive learning outcomes were found in the case of all studies, but often, cognitive and motivational outcomes were focused on simultaneously. Cognitive learning outcomes almost always focused on a conceptual understanding of the topic (scientific knowledge in one or other field of studies). Only in the case of one study was the aim to improve students' computational thinking skills. In one study, the effect of using AR was evaluated on both inquiry skills and conceptual understanding. In a few studies, the focus was also on emotional goals. For example, Efstathiou et al. [26] and Kyza and Georgiou [27] studied in related studies how students' empathy is achieved using AR field trips in history. In addition, one study focused on students' metacognitive skills (learning strategies) and another on collaborational goals (to afford students' collaboration).

Table 1. Purposes of using mobile augmented reality (AR) in inquiry-based learning.

\begin{tabular}{cccccc}
\hline Article & Cognitive & Metacognitive & Motivational & Emotional & Collaborational \\
\hline Efstathiou et al. [26] & $\mathrm{X}$ & & $\mathrm{X}$ & \\
\hline Kyza and Georgiou [27] & $\mathrm{X}$ & & $\mathrm{X}$ & \\
\hline Chiu et al. [28] & $\mathrm{X}$ & & & \\
\hline Singh et al. [29] & $\mathrm{X}$ & $\mathrm{X}$ & $\mathrm{X}$ & $\mathrm{X}$ \\
\hline Gardeli and Vosinakis [30] & $\mathrm{X}$ & $\mathrm{X}$ & & \\
\hline Patrício et al. [31] & $\mathrm{X}$ & & & \\
\hline Reza et al. [32] & $\mathrm{X}$ & $\mathrm{X}$ & & \\
\hline Bhagat et al. [33] & $\mathrm{X}$ & & & \\
\hline
\end{tabular}


Table 1. Cont.

\begin{tabular}{|c|c|c|c|c|c|}
\hline Article & Cognitive & Metacognitive & Motivational & Emotional & Collaborational \\
\hline Ibáñez et al. [34] & $x$ & & $x$ & & \\
\hline Lindner [35] & $x$ & & $x$ & & \\
\hline Estapa and Nadolny [36] & $x$ & & $x$ & & \\
\hline Hwang [37] & $x$ & & $x$ & & \\
\hline Huang et al. [38] & $x$ & & & $x$ & \\
\hline Ibáñez et al. [39] & $x$ & $x$ & $x$ & & \\
\hline Hsiao et al. [40] & $x$ & & $x$ & & \\
\hline
\end{tabular}

\subsection{Potential Advantages of Combining AR with Inquiry-Based Learning}

In the introduction of the article, we identified several affordances of AR. Some of them could be applied in the context of inquiry-based learning as well. In Table 2, we give an overview of how the affordances of the mobile AR have been used in the inquiry-based learning context in the 15 articles found in the current literature review. It was found that the Conceptualization phase was used in all of the 15 cases. Usually, the AR environment was applied to simply collect some information about the studied objects, but in four studies, a gamified approach was used. In three of these cases, students took the role of scientists who discovered the world around them, e.g., explored butterflies in different ecological locations (see [37]). In one case, they simply tried to catch different planets in an augmented solar system and got points (see [31]). Inquiry-based learning was a bit less used in the Orientation phase (nine articles), in the Investigation phase (nine articles), in the Conclusion phase (seven articles) and in the Discussion phase (seven articles). AR was mostly implemented in the Conceptualization phase (14 articles), and following the Investigation phase (eight articles), and Orientation and Conclusion phases (both in two articles). We found no studies that used AR in the Discussion phase. All five phases of inquiry were reported only in five articles, but none of these studies implemented AR in all of the phases. Two of these five papers were published by the same research group and they implemented AR in the Orientation, Conceptualization and Investigation phases. In addition, these two studies $([26,27])$ were the only ones that used AR in the Orientation phase to assign students into roles and to guide them to the task. Seven studies reported the use of AR together with two different phases of inquiry-based learning. The Conceptualization and the Investigation phase were applied together the most (six articles). For example, Ibáñez et al. [39] used AR to give students the background information and to experiment with electrical circuits and take measurements. Another example of using the Conceptualization and Investigation phases together with AR is from Singh et al. [29], who used AR to observe historical buildings that no longer existed to reflect the changes over time and to collect different data. The Conceptualization and the Conclusion phases were used together with AR in one case. Huang, Chen and Chou [38] used AR to observe, search and memorize information, and then later for a test to give students immediate feedback. As well as that, AR was implemented with the Conclusion phase in another study to give real-time feedback.

Table 2. The use of mobile AR in different phases of inquiry-based learning (AR-AR was used in the phase, $X$ - the phase was used in the scenario but AR was not used in this phase).

\begin{tabular}{cccccc}
\hline Article & Cognitive & Metacognitive & Motivational & Emotional & Collaborational \\
\hline Efstathiou et al. [26] & AR & AR & AR & X & X \\
\hline Kyza and Georgiou [27] & AR & AR & AR & X & $X$ \\
\hline Chiu et al. [28] & X & AR & AR & X & $X$ \\
\hline Singh et al. [29] & X & AR & AR & $X$ & $X$ \\
\hline
\end{tabular}


Table 2. Cont.

\begin{tabular}{|c|c|c|c|c|c|}
\hline Article & Cognitive & Metacognitive & Motivational & Emotional & Collaborational \\
\hline Gardeli and Vosinakis [30] & & $\mathrm{AR}$ & & & $x$ \\
\hline Patrício et al. [31] & & AR & & & $?$ \\
\hline Reza et al. [32] & & AR & & & \\
\hline Bhagat et al. [33] & & $x$ & & AR & \\
\hline Ibáñez et al. [34] & & $\mathrm{AR}$ & $\mathrm{AR}$ & & \\
\hline Lindner [35] & & $\mathrm{AR}$ & $\mathrm{AR}$ & & $x$ \\
\hline Estapa and Nadolny [36] & $x$ & $\mathrm{AR}$ & $x$ & & \\
\hline Hwang [37] & $x$ & $\mathrm{AR}$ & & & \\
\hline Huang et al. [38] & $x$ & $\mathrm{AR}$ & & $\mathrm{AR}$ & $?^{1}$ \\
\hline Ibáñez et al. [39] & $x$ & $\mathrm{AR}$ & $\mathrm{AR}$ & & \\
\hline Hsiao et al. [40] & $x$ & AR & $\mathrm{AR}$ & $x$ & $x$ \\
\hline
\end{tabular}

\subsection{Characteristics of AR-Based Applications Used for Inquiry-Based Learning}

The literature review revealed two main characteristics of AR-based applications described in the articles (see Table 3). The first was the method by which AR was implemented. Eight studies used marker-based applications: seven of them used an image-based recognition, and only one used the QR-code. For example, image-based markers were used to learn about the appearance of different butterfly species in live motion using 3D animations (see [33]), or to observe the properties of 2D book images as 3D geometric shapes (see [32]). There were six studies that used markerless applications, which were mostly location-based and needed GPS (five studies). For example, AR was implemented in specific locations in two different cases to learn about history. In one of these cases, students had to pass different hotspots in a Neolithic settlement in Cyprus to learn about how Neolithic people lived in the past (see [26]). Moreover, one study used sensors as physical inputs. For example, students had to place the hot water jars near the temperature sensor to increase the gas temperature, and thereby learn about gas properties (see [28]).

Table 3. Characteristics of the AR-based applications used for inquiry-based learning.

\begin{tabular}{|c|c|c|c|}
\hline \multirow{2}{*}{ Article } & \multicolumn{2}{|c|}{ AR Triggering Methods } & \multirow{2}{*}{ Location of the Activity } \\
\hline & Marker-Based & Markerless & \\
\hline Efstathiou et al. [26] & & GPS & outdoors \\
\hline Kyza and Georgiou [27] & & GPS & outdoors \\
\hline Chiu et al. [28] & & sensors & indoors \\
\hline Singh et al. [29] & & GPS & out- and indoors \\
\hline Gardeli and Vosinakis [30] & image & & indoors \\
\hline Patrício et al. [31] & & GPS & outdoors \\
\hline Reza et al. [32] & image & & indoors \\
\hline Bhagat et al. [33] & image & & indoors \\
\hline Ibáñez et al. [34] & image & & indoors \\
\hline Lindner [35] & image & & indoors \\
\hline Estapa and Nadolny [36] & image & & out- and indoors \\
\hline Hwang [37] & QR-code & & outdoors \\
\hline Huang et al. [38] & $?^{1}$ & $?$ & outdoors \\
\hline Ibáñez et al. [39] & image & & indoors \\
\hline Hsiao et al. [40] & & $?$ & indoors \\
\hline
\end{tabular}

\footnotetext{
${ }^{1}$ The information was not evident in the article.
} 
Most of the studies were carried out indoors (eight articles) and fewer studies were carried out in outdoor environments (five articles). Indoor studies were mostly carried out during class, with a few exceptions-for instance, [40] a weather simulation AR system was developed for students to learn at home, at school or at a museum. Outdoor studies were carried out in specific locations, such as in historical places, or in botanical or butterfly gardens-for example, AR was used in botanical gardens to learn about environmental ecology; at different spots, students were provided with information about the objects. They had to follow a certain route there to learn about rainforests, lowlands and plants (see [38]). Moreover, two studies used both outdoor and indoor environments. One such kind of study was carried out in mathematics during a spring break trip from Iowa, USA to Cancun, Mexico. During the trip, students had to solve mathematical problems on the topics that were contextualized in the places they visited (see [36]).

\subsection{Effects of Using AR in an Inquiry-Based Learning Process}

Several previously-published literature reviews revealed that AR has mostly been used to measure students' cognitive and motivational outcomes (see $[15,16,18]$ ). In Table 4 , we give an overview of the effects of applying AR in inquiry-based learning in the 15 articles that were analyzed in this literature review. We found 12 papers that focused on cognitive effects, eight papers on motivational effects and five papers on emotional effects. We found that no effects were reported in the case of metacognitive aspects, and only one paper evaluated student collaboration. It was common that these effects were not evaluated alone, but several were included several instead. There were three papers that concentrated on only one effect. We also noticed that one paper's purpose was that students achieve cognitive learning goals, but it reported no measured effects. However, nine papers evaluated two effects together. Cognitive and motivational effects were evaluated together in eight of these studies. There were fewer studies (four articles) that concentrated on cognitive and emotional effects.

In three of the studies measuring cognitive effects, the focus was on conceptual understanding. For example, [26] evaluated students' conceptual understanding in history and carried out pre- and post-tests, and also interviewed students. The experimental group in their study used AR technology, and the control group was guided by their teacher. In both cases, students went on a field trip in a Neolithic settlement, and they had to explain why the Neolithic people had chosen the location for their settlement. Afterwards, the differences in pre- and post-tests and student interviews were analyzed, and it was found that the development of conceptual understanding improved to a greater extent when using AR technology. Moreover, improving the knowledge of learning topics was the focus in two studies. For instance, [34] measured the effects on knowledge of geometry concepts in public and private school students. They used multiple-choice pre- and post-tests to evaluate the effects. Students who used AR-based applications were able to visualize 3D geometric shapes from all sides in real time, but students who used the web-based application could only use static geometric shapes without interaction. As a result, they found that students who used AR performed better than those who used a web-based application, and the use of AR in the learning process was more effective in public schools.

In the cases of evaluating motivational aspects, the focus was mostly on attention (four studies), relevance and satisfaction (both in three studies). As well as that, these motivational aspects were mainly evaluated together. Attention, relevance, confidence and satisfaction were evaluated altogether in two papers. Both of them used the Instructional Materials Motivation Survey (IMMS) as a research instrument for examining motivation. The survey consisted of different statements, and students had to answer the questionnaire using the five-point Likert scale. In the study from Ibáñez et al. [38], students completed the survey after applying the AR application to discover the basic principles of electricity. The authors reported that students were moderately highly motivated toward the use of the AR application. In the study from Bhagat et al. [33], students completed the survey after taking the AR-based formative assessment test about butterflies. The motivation questionnaire revealed that there was a positive effect on motivation for students who used AR. 
In two of the papers that focused on emotional effects, students' enjoyment levels were measured. For instance, students had to create and solve a simple AR-based game in moves in teams, and their enjoyment levels were evaluated afterwards using an anonymous questionnaire (see [30]). The authors reported that the students' enjoyment levels were high as $89.4 \%$; all of the answers were five out of five on the Likert scale. The same study was the only one that also focused on collaborational aspects. They noticed different collaboration patterns during the game and suggested that this needs to be further studied. Another example of evaluating enjoyment levels was carried out by Patricio, Costa and Manso [31]. Students played an AR-based game in which they had to catch as many planets as possible and collect points. Their enjoyment levels were measured after by taking inquiries. It was found that more than $85 \%$ of the players had an enjoyable experience.

Table 4. The effects of applying AR in inquiry-based learning*.

\begin{tabular}{|c|c|c|c|c|}
\hline Article & Cognitive $^{1}$ & Motivational & Emotional & Collaborational \\
\hline Efstathiou et al. [26] & $\begin{array}{c}\text { Conceptual } \\
\text { understanding, historical } \\
\text { contextualization, } \\
\text { perspective-taking }\end{array}$ & & $\begin{array}{l}\text { Affective } \\
\text { connection }\end{array}$ & \\
\hline Kyza and Georgiou [27] & $\begin{array}{l}\text { Conceptual understanding, } \\
\text { problem-solving }\end{array}$ & & Historical empathy & \\
\hline Chiu et al. [28] & Constructing explanations & & & \\
\hline \multicolumn{5}{|l|}{ Singh et al. [29] } \\
\hline Gardeli and Vosinakis [30] & Learnability & & Enjoyment & Collaboration \\
\hline Patrício et al. [31] & & & Enjoyment & \\
\hline Reza et al. [32] & Mastery in geometry & & & \\
\hline Bhagat et al. [33] & Classification of objects & $\begin{array}{l}\text { Attention, relevance, confidence, } \\
\text { satisfaction }\end{array}$ & & \\
\hline Ibáñez et al. [34] & $\begin{array}{l}\text { Knowledge of geometry } \\
\text { concepts }\end{array}$ & Attention, relevance, satisfaction & & \\
\hline Lindner [35] & $\begin{array}{c}\text { Students perceived } \\
\text { comprehension of topics }\end{array}$ & Students' interest & & \\
\hline Estapa and Nadolny [36] & $\begin{array}{l}\text { Technical and conceptual } \\
\text { understanding of } \\
\text { mathematical processes }\end{array}$ & Attention & & \\
\hline Hwang [37] & Knowledge of butterflies & Science learning Attitude & & \\
\hline Huang et al. [38] & Perceived competency & Engagement & $\begin{array}{c}\text { Self-assessed } \\
\text { positive emotions }\end{array}$ & \\
\hline Ibáñez et al. [39] & $\begin{array}{l}\text { Learning outcomes } \\
\text { moderately correlated } \\
\text { with motivation and } \\
\text { self-regulation }\end{array}$ & $\begin{array}{l}\text { Attention, relevance, confidence, } \\
\text { satisfaction. Motivation } \\
\text { moderately correlated with } \\
\text { learning outcomes }\end{array}$ & & \\
\hline Hsiao et al. [40] & Creativity & Participation level & & \\
\hline
\end{tabular}

\section{Discussion}

Our study focused first on finding the purposes of using mobile AR in inquiry-based learning. The analysis showed that the focus of the studies has been mainly on cognitive goals. This is in line with the other systematic literature reviews that also conclude that a particular form of AR is used to achieve cognitive learning outcomes, e.g., academic performance [15], academic achievement [17,19], knowledge comprehension [16] and conceptual understanding [18]. Altinpulluk [17], Yilmaz [19], and Ibáñez and Delgado-Kloos [18] found, in addition, that AR has also had an effect on motivation and satisfaction. In line with this, we found in our review that often, AR had a motivational effect in the context of inquiry-based learning. Ibáñez and Delgado-Kloos [18] also mentioned positive effects on enjoyment, which is in accordance with our theoretical framework describing emotional learning outcomes that were mentioned in a few articles in our study as well. Therefore, we can conclude that AR has been used in inquiry-based learning to achieve the same purposes that have been mentioned in 
previous literature reviews. However, two more purposes were revealed that haven't been specified in other studies. First, one study also focused on developing learners' metacognitive skills and another on collaboration skills in the context of inquiry-based learning. These seem to be emerging purposes that could be highlighted more in further studies and developmental work on AR scenarios.

The second research question in our study focused on the affordances of AR that could provide possibilities for combining AR with inquiry-based learning. It appears that inquiry-based learning has been applied in most of the found studies at a limited level. Only five studies out of 15 guided learners to all five phases of inquiry according to the inquiry cycle described by Pedaste et al. [25]. The conceptualization phase was the only one that was present in all found studies. In most of these studies, except one, AR was integrated into the learning process in this phase. It shows that AR could be easily used to learn something about objects or processes to increase conceptual understanding. In addition, about half of the studies implemented AR scenarios in the Investigation phase, but only two studies did it in either the Orientation or Conclusion phase. Surprisingly, AR was applied in the Discussion phase in no studies, although this phase was supported in about half of the studies. Our findings reveal that AR has been used in inquiry-based learning at a quite limited level. According to Wu et al. [14], the main affordances of AR lie in visualizing objects and allowing interaction with them, which are mainly needed in both the Conceptualization and Investigation phases; however, the third affordance of collaborative and situation learning could be perfectly applied in all other inquiry phases as well. For example, AR could be used in the Orientation phase to immerse learners in the situation where the problem appears, as was done in the case of a few studies found in the current literature review. However, the same scenario could also be used in the conclusion phase, where the learners could be situated at the initial situation where the problem appeared, but now with the information they collected in the Investigation phase to enable them to make a conclusion. The affordance to support collaborative learning could be well applied in the Discussion phase. For example, learners can share their augmented view with peers in order to discuss what they have found, what could be further done, etc. Thus, in conclusion, the affordances of AR could be easily used on all phases of inquiry-based learning, but, according to our literature review, there are no studies that have done this to date. The full potential of AR in inquiry-based learning needs to be revealed in further studies. In further studies, it would be especially important to concentrate on evaluating inquiry skills because, according to our literature review, the studies usually did not evaluate the effect of the interventions on inquiry skills. The main focus of the evaluation was on the conceptual understanding of knowledge and motivation.

Third, our review focused on the characteristics of AR-based applications used in the context of inquiry-based learning. The analysis revealed that diversity has been quite high in both marker-based versus markerless (see [11]), and image-based indoors versus location-based outdoors solutions (see [12]). Regarding AR triggering methods, both marker-based and markerless solutions were often in use, although image-based markers had been used a bit more often. This is surprising because we focused on mobile AR, which enables us to develop scenarios for markerless GPS-based learning. GPS-based AR was used only in four studies out of the 15 in our review. The GPS-based solutions could be used only outdoors, and the finding might also reflect the limitations schools might have in organizing studies outside the school building, although this might be beneficial for students' health and allow for better immersion in real-world settings. Therefore, we suggest focusing more on developing GPS-based AR solutions for learning outdoors. For example, learners might get acquainted with a situation outdoors using AR in the Orientation phase by augmenting the real-world environment with information about objects, or videos of the same environment from the past or the future according to different predictions. Next, they could learn about different objects and processes in the learning scenario in the Conceptualization phases. After that, the learners could run some interactive experiments in AR and then draw conclusions in the Conclusion phase by selecting different developed scenarios in AR. All of these phases could be communicated and reflected on with peers in 
the Discussion phase in order to learn more about the studied case, but also to achieve an increase in inquiry skills.

Our fourth research question was asked about the effects revealed by applying AR in inquiry-based learning. As it was already found that inquiry skills were not assessed in almost all of the studies, we looked more closely at the more general cognitive, metacognitive, motivational, emotional and collaborational effects. Most of the studies confirmed the positive effect of AR scenarios on one or more learning outcomes. The diversity of cognitive effects was quite high-knowledge, conceptual understanding and the ability to take different perspectives into account. Motivational effect was operationalized through increases in attention, students' interest, attitudes, satisfaction, engagement and levels of participation. The positive emotional effect was measured based on enjoyment, empathy, affective connection and positive emotions. It was found that the motivational effect usually appeared if the scenario focused on several inquiry phases, and in all cases where AR was also used in the Orientation or Conclusion phase. For some reason, the motivational effects were found mainly in cases of image-based AR technologies and less often in cases of GPS-based AR. In contrast, the results revealed that GPS-based markerless AR solutions often had positive effects on emotional aspects and that this was not the case for marker-based solutions. This does not show that the marker-based and markerless AR solutions do have different effects on learners' motivation and emotion, but this needs to be studied more in the future. Currently, the number of studies is too small to make any generalizations.

\section{Conclusions}

Our study enabled us to answer all four research questions formulated in the beginning. First, we found that AR has been, in the context of inquiry-based learning, mainly used to achieve different cognitive learning outcomes, or higher motivation and more positive emotions. Metacognitive skills and collaboration have not often been in focus. Second, the affordances of AR have been applied at a limited level by focusing mainly on the Conceptualization and Investigation phases of the inquiry process. The Orientation phase has been in focus much less than expected, and the Discussion phase has been the focus of the studies, but AR has never been used to support discussion in the 15 studies found in the current literature review. Third, the variety of technical solutions for implementing AR in inquiry-based learning is quite diverse. Both maker-based and markerless solutions have been used successfully to achieve cognitive learning outcomes. However, for some reason, marker-based solutions have shown a greater effect on learners' motivation, and markerless, GPS-based solutions a greater effect on positive emotions. This would be an interesting question to study further. In addition, further studies need to focus more on applying AR in different phases of inquiry and on assessing inquiry skills as well. Currently, none of the studies specifically evaluated the learning gain in inquiry skills.

Although the findings of the current study allow us to make several suggestions, it's important to note that there are some limitations that have to be taken into account when applying the conclusions in the following studies. First, our literature review revealed only 15 studies that were in accordance with the inclusion criteria. This shows that this field of study is rather new and some of the potential effects of using AR in inquiry-based learning will be discovered in the future. In addition, the technology used for AR is improving very fast and, therefore, the affordances of mobile AR in education might be extended in the coming years. One more limitation of the current literature review is that the studies were based on quite small samples. For example, 10 of the studies considered the small sample size as a limitation to generalizing their findings, but sample size was quite small in all of the studies. This means that their findings may be relevant only to a specific group of students. One more important limitation is the novelty effect, which has been reported in six papers. Several studies also had concerns regarding the durability of the interventions. Only one paper reported a long-term study. According to this, long-term studies are needed in order to understand their findings better.

In conclusion, the systematic literature review shows that $\mathrm{AR}$ is, according to its affordances, a good tool to support inquiry-based learning. It could be applied both indoors and outdoors and 
the cognitive learning outcomes could be strengthened through positive effects on motivation and emotions. However, the effects of metacognitive and collaboration skills still need to be revealed in studies that focus more clearly on these aspects as well.

Author Contributions: Conceptualization, M.P., G.M. and T.J.; Data curation, G.M.; Formal analysis, M.P., G.M. and T.J.; Methodology, M.P., G.M. and T.J.; Supervision, M.P.; Writing - original draft, M.P. and G.M.; Writing review \& editing, M.P., G.M. and T.J. All authors have read and agreed to the published version of the manuscript.

Funding: This research was partly funded by the University of Tartu, research grant awarded by the Development Fund of the Institute of Education. The development of the framework was partly funded with support from the European Commission to the EL-STEM (Enlivened Laboratories within STEM Education Motivating EU students to choosing STEM studies \& careers and improving their performance in courses related to STEM education) Erasmus+ project (project number 2017-1-CY01-KA201-026775). The development of the methods used in the study were partly funded by the grant Smart technologies and digital literacy in promoting a change of learning (IUT34-6) financed by the Estonian Research Council. This article reflects the views only of the authors, and the Commission cannot be held responsible for any use which may be made of the information contained therein. We thank all partners of the mentioned projects for their valuable contribution in developing the framework.

Conflicts of Interest: The authors declare no conflict of interest.

\section{References}

1. Gibson, J.J. The Ecological Approach to Visual Perception; Houghton Mifflin: Boston, MA, USA, 1979. [CrossRef]

2. Hutchby, I. Technologies texts and affordances. Sociology 2001, 35, 441-456. [CrossRef]

3. Leijen, Ä.; Pedaste, M.; Lepp, L. Teacher agency following the ecological model: How it is achieved and how it could be strengthened by different types of reflection. Br. J. Educ. Stud. 2020, 1-16. [CrossRef]

4. Priestley, M.; Biesta, G.J.J.; Robinson, S. Teacher Agency: An Ecological Approach; Bloomsbury Academic: London, UK, 2015.

5. Pedaste, M.; Leijen, Ä. How can advanced technologies support the contemporary learning approach? In Proceedings of the 18th IEEE International Conference on Advanced Learning Technologies (ICALT), Mumbai, India, 9-13 July 2018; pp. 21-23. [CrossRef]

6. Hooshyar, D.; Kori, K.; Pedaste, M.; Saks, K.; Leijen, Ä.; Bardone, E.; Wang, M.; Chounta, I.A. Open learner models in higher education: A visual systematic review. Comput. Educ. 2020, in press.

7. Panadero, E. A Review of self-regulated learning: Six models and four directions for research. Front Psychol. 2017, 8. [CrossRef]

8. Pedaste, M.; Must, O.; Leijen, Ä.; Mäeots, M.; Siiman, L.; Kori, K.; Adov, L. Profiles of students who use mobile devices for the purposes of learning science and mathematics. Estonian J. Educ. 2017, 5, 99-129. [CrossRef]

9. Azuma, R.T. A survey of augmented reality. Presence-Teleoperators Virtual Environ. 1997, 6, 355-385. [CrossRef]

10. Hariduse tehnoloogiakompass (In Estonian). Available online: https://kompass.hitsa.ee/ (accessed on 28 February 2020).

11. Johnson, L.; Laurence, F.; Smith, R.; Stone, S. The 2010 Horizon Report; The New Media Consortium: Austin, TX, USA, 2010.

12. Cheng, K.-H.; Tsai, C.-C. Affordances of augmented reality in science learning: Suggestions for future research. J. Sci. Educ. Technol. 2013, 22, 449-462. [CrossRef]

13. Nowacki, P.; Woda, M. Capabilities of ARCore and ARKit Platforms for AR/VR applications. In Engineering in Dependability of Computer Systems and Networks. DepCoS-RELCOMEX 2019. 2020 Advances in Intelligent Systems and Computing; Zamojski, W., Mazurkiewicz, J., Sugier, J., Walkowiak, T., Kacprzyk, J., Eds.; Springer: Berlin/Heidelberg, Germany, 2020; Volume 987, pp. 358-370. [CrossRef]

14. Wu, H.-K.; Lee, S.W.-Y. Chang, H.-Y.; Liang, J.-C. Current status, opportunities and challenges of augmented reality in education. Comput. Educ. 2013, 62, 41-49. [CrossRef]

15. Akçayır, M.; Akçayır, G. Advantages and challenges associated with augmented reality for education: A systematic review of the literature. Educ. Res. Rev. 2017, 20, 1-11. [CrossRef]

16. Saltan, F.; Arslan, Ö.E. The use of augmented reality in formal education: A scoping review. EURASIA J. Math. Sci. Technol. Educ. 2017, 13, 503-520. [CrossRef]

17. Altinpulluk, H. Determining the trends of using augmented reality in education between 2006-2016. Educ. Inf. Technol. 2019, 24, 1089-1114. [CrossRef] 
18. Ibanez, M.; Delgado-Kloos, C. Augmented reality for STEM learning: A systematic review. Comput. Educ. 2018, 123, 109-123. [CrossRef]

19. Yilmaz, M.R. Augmented Reality Trends in Education between 2016 and 2017 Years. State of the Art Virtual Reality and Augmented Reality Knowhow; IntechOpen: London, UK, 2018. [CrossRef]

20. Cai, S.; Liu, E.; Shen, Y.; Liu, C.; Li, S.; Shen, Y. Probability learning in mathematics using augmented reality: Impact on student's learning gains and attitudes. Interact. Learn. Environ. 2019. [CrossRef]

21. Keselman, A. Supporting inquiry learning by promoting normative understanding of multivariable causality. J. Res. Sci. Teach. 2003, 40, 898-921. [CrossRef]

22. Pedaste, M.; Mäeots, M.; Leijen, Ä.; Sarapuu, T. Improving students' inquiry skills through reflection and self-regulation scaffolds. Technol. Instr. Cogn. Learn. 2012, 9, 81-95.

23. De Jong, T.; van Joolingen, W.R. Scientific discovery learning with computer simulations of conceptual domains. Rev. Educ. Res. 1998, 68, 179-202. [CrossRef]

24. Wilhelm, P.; Beishuizen, J.J. Content effects in self-directed inductive learning. Learn. Instr. 2003, 13, 381-402. [CrossRef]

25. Pedaste, M.; Mäeots, M.; Siiman, L.A.; de Jong, T.; van Riesen, S.A.; Kamp, E.T.; Manoli, C.C.; Zacharia, Z.C.; Tsourlidaki, E. Phases of inquiry-based learning: Definitions and the inquiry cycle. Educ. Res. Rev. 2015, 14, 47-61. [CrossRef]

26. Efstathiou, I.; Kyza, E.A.; Georgiou, Y. An inquiry-based augmented reality mobile learning approach to fostering primary school students' historical reasoning in non-formal settings. Interact. Learn. Environ. 2018, 26, 22-41. [CrossRef]

27. Kyza, E.A.; Georgiou, Y. Scaffolding augmented reality inquiry learning: the design and investigation of the TraceReaders location-based, augmented reality platform. Interact. Learn. Environ. 2019, 27, 211-225. [CrossRef]

28. Chiu, C.L.; DeJaegher, C.J.; Chao, J. The effects of augmented virtual science laboratories on middle school students' understanding of gas properties. Comput. Educ. 2015, 85, 59-73. [CrossRef]

29. Singh, G.; Bowman, D.A.; Hicks, D.; Cline, D.; Ogle, J.T.; Johnson, A.; Zlokas, R.; Tucker, T.; Ragan, E.D. CI-Spy: Designing a mobile augmented reality system for scaffolding historical inquiry learning. In Proceedings of the 2015 IEEE International Symposium on Mixed and Augmented Reality - Media, Art, Social Science, Humanities and Design, Fukuoka, Japan, 29 September-3 October 2015; pp. 9-14.

30. Gardeli, A.; Vosinakis, S. ARQuest: A tangible augmented reality approach to developing computational thinking skills. In Proceedings of the 11th International Conference on Virtual Worlds and Games for Serious Applications (VS-Games), Vienna, Austria, 4-6 September 2019; pp. 1-8. [CrossRef]

31. Patrício, J.M.; Costa, M.C.; Manso, A. A Gamified mobile augmented reality system for the teaching of astronomical concepts. In Proceedings of the 14th Iberian Conference on Information Systems and Technologies (CISTI), Coimbra, Portugal, 19-22 June 2019; pp. 1-5. [CrossRef]

32. Reza, A.; Siti, L.; Ramadiani, R.; Fahrul, A. "Magic Boosed" an elementary school geometry textbook with marker-based augmented reality. TELKOMNIKA Indones. J. Electr. Eng. 2019, 17, 1242-1249. [CrossRef]

33. Bhagat, K.K.; Liou, W.-K.; Spector, J.M.; Chang, C.-Y. To use augmented reality or not in formative assessment: A comparative study. Interact. Learn. Environ. 2019, 27, 830-840. [CrossRef]

34. Ibáñez, M.B.; Portillo, A.U.; Cabada, R.Z.; Barrón, M.L. Impact of augmented reality technology on academic achievement and motivation of students from public and private Mexican schools. A case study in a middle-school geometry course. Comput. Educ. 2020, 145, 1-9. [CrossRef]

35. Lindner, C.; Rienow, A.; Jürgens, C. Augmented Reality applications as digital experiments for education-An example in the Earth-Moon system. Acta Astronaut. 2019, 161, 66-74. [CrossRef]

36. Estapa, A.; Nadolny, L. The Effect of an augmented reality enhanced mathematics lesson on student achievement and motivation. J. STEM Educ. 2015, 16, 40-48.

37. Hwang, G.-J.; Wu, P.-H.; Chen, C.-C.; Tu, N.-T. Effects of an augmented reality-based educational game on students' learning achievements and attitudes in real-world observations. Interact. Learn. Environ. 2016, 24, 1895-1906. [CrossRef]

38. Huang, T.-C.; Chen, C.-C.; Chou, Y.-W. Animating eco-education: To see, feel, and discover in an augmented reality-based experiential learning environment. Comput. Educ. 2016, 96, 72-82. [CrossRef] 
39. Ibáñez, M.; Di-Serio, Á.; Villarán-Molina, D.; Delgado-Kloos, C. Augmented reality-based simulators as discovery learning tools: An empirical study. IEEE Trans. Educ. 2015, 58, 208-213. [CrossRef]

40. Hsiao, H.-S.; Chang, C.-S.; Lin, C.-Y.; Wang, Y.-Z. Weather observers: a manipulative augmented reality system for weather simulations at home, in the classroom, and at museum. Interact. Learn. Environ. 2016, 24, 205-223. [CrossRef] 